\title{
Inatualidade e anacronismo na fotografia contemporânea
}

\author{
Fernando Gonçalves
}

Resumo: O artigo discute as condições de individuação da chamada fotografia contemporânea a partir do exame da noção de anacronismo em diferentes autores e de obras de artistas como Jeff Wall e Cindy Sherman. A construção da discursividade visual na arte como questão de comunicação é formulada através da ideia de que haveria uma inatualidade em certas imagens do presente, percebida pelos traços persistentes de questões e de imagens de outros tempos, particularmente relativos à história da arte. A pertinência de se pensar a experiência do fotográfico na arte reside nas contribuições que esta apresenta para se discutir aspectos propriamente comunicativos da fotografia, particularmente a representação e as operações que nela ordenam o visível e mediam nossas relações com o mundo através da imagem.

Palavras-chave: fotografia; história; anacronismo; representação; arte contemporânea.

Abstract: Unpresentness and anachronism in the contemporary photography - This paper discusses the individuation conditions of the so-called contemporary photography by examining the notion of anachronism in different artworks and authors as Jeff Wall and Cindy Sherman. The construction of visual discursivity in art as a matter of communication comes from the idea that it would exist, in nowadays particular images, an unpresentness perceivable through persistent pictorial traces and issues of other times, particularly in art history. The relevance of thinking on the experience of photography in art points to its contributions for discussing communicative aspects of photography, mostly the representation that order the visible, as well as their operations that mediate our relationship with the world through the image.

Keywords: photography; history; anachronism; representation; contemporary art.

\section{Introdução}

Alguns dos traços presentes na produção artística contemporânea com fotografia apontam para uma recorrência de temas, categorias e questões da história da arte e que podem ser vistas pelo menos desde a pintura do século XVII e na própria fotografia 
do século XIX. A questão se coloca a partir da constatação de que grande parte da produção artística contemporânea em fotografia parece realizar uma discussão sobre a representação e inventariar nossos modos de visão e de existência em nossa história recente, através de referências a imagens e questões de outros tempos e da arte.

A pertinência de se pensar a experiência do fotográfico no âmbito da arte reside na possibilidade de se pensar aspectos propriamente comunicativos da discursividade visual fotográfica, especialmente a questão da narrativa e da produção de sentido para a experiência a partir da análise das operações que tornam possível o ordenamento do visível e a mediação de nossas relações com o mundo através da imagem.

Para autores como Fried (2012) e Poivert (2010), é relevante o fato de a fotografia contemporânea ${ }^{1}$ fundar as bases de sua atualidade numa relação de contemporaneidade com a própria arte e sua história. Ou seja, a fotografia teria nas questões da arte um lugar privilegiado, embora não exclusivo, para repensar seu estatuto, suas funções e modos de presença. A persistência de traços e de questões de outros tempos nas imagens do presente no campo da arte seria, portanto, um ato intencionado que permitiria tornar a imagem um problema e ao mesmo tempo um modo particular de mediar a experiência.

Por meio desse ato intencionado, as imagens podem ser consideradas como inscritas num conjunto de tensões e relações muito próximo daquilo que Jacques Rancière chamou de partilha do sensível: "sistema de evidências sensíveis que revela, ao mesmo tempo, a existência de um comum e dos recortes que nele definem lugares e partes respectivas" (RANCIÈRE, 2012, p. 15). O texto busca então mostrar que a fotografia na arte contemporânea constitui uma evidência desses processos de partilha, uma vez que problematiza noções como narrativa e representação e propõe outras formas de aludir ao real e de enunciá-lo através da imagem.

A aposta é de que a fotografia contemporânea proporia outras formas de regulagem nas relações entre visível e dizível na imagem. Contudo, tal aposta nos leva à necessidade de problematizar, de partida, a própria condição contemporânea da fotografia como modo autônomo ou inaugural de partilha e como condição mesma de investigação de sua individuação na arte. Pelo termo individuação entendo, apoiado em Lissovsky (2008), o processo de diferenciação que, no âmbito das experiências do fotográfico, definiria particularmente o que é visível e invisível em dada experiência visual e que influenciaria nossa experiência de tempo e de espaço bem como nossas visões de mundo.

O objetivo do texto será precisamente evidenciar como a recorrência de temas e questões da história da arte seria um dos vetores que ajudam a entender os processos de individuação da fotografia na arte contemporânea através da noção de anacronismo.

1 O termo fotografia contemporânea é usado por autores como Rouillé e Poivert para designar não toda a experiência do fotográfico na atualidade, dentro e fora da arte, mas majoritariamente a fotografia no campo da arte. Apesar disso, esta forma de manifestação da fotografia dialoga com as imagens do cotidiano e da mídia, além das da própria arte, na medida em que realizam uma espécie de inventário e releitura da própria imagem como representação. 
O anacronismo vem se tornando crucial nos estudos da imagem nos campos da arte e da comunicação e implica a ideia de uma atualidade do passado e de uma inatualidade do presente e que marca, no campo das imagens, aquilo que seria próprio desta em sua condição de objeto ao mesmo tempo técnico, artístico, social, histórico e comunicativo.

Partindo também da noção de contemporâneo em Agamben (2009), o texto busca ainda problematizar a experiência da fotografia na arte contemporânea com uma experiência específica de nosso presente. Para tanto, o texto partirá de duas premissas: a primeira, apoiada na noção de origem em Benjamin (1993, 2011), de que o tempo histórico não é linear ou único, mas processual e saturado de múltiplas temporalidades; e a segunda, apoiada na ideia de anacronismo em Didi-Huberman, Rancière e Daniel Arrasse, segundo a qual a experiência da imagem no tempo pode se caracterizar por regularidades enunciativas ${ }^{2}$ que constroem condições semelhantes de dar a ver o sensível e de apreendê-lo em diferentes momentos históricos.

Dessa forma, buscando relacionar algumas experiências da imagem no âmbito da arte, o artigo se interessará por discutir as condições de possibilidade da fotografia contemporânea a partir dos anacronismos que parecem participar da construção das discursividades visuais da fotografia na arte em nosso presente e algumas de suas implicações para um pensamento sobre a imagem no campo da comunicação.

\section{A fotografia na arte como questão de comunicação}

Os usos da fotografia na arte podem ser tomados como uma forma de investigar as formas de representação e de regulação de nossas relações com o mundo através da imagem. Nesse sentido, algumas das práticas artísticas contemporâneas com fotografia vêm se constituindo como aquilo que Didi-Huberman (2011, p. 64) chamou de sintoma, uma suspensão "no curso normal da representação", ou seja, como uma inoculação de um pensamento crítico sobre a representação na imagem e por meio da própria imagem.

Embora a arte não detenha o privilégio da criação, podemos observar nas práticas artísticas contemporâneas e nas novas teorias da história da arte um grande interesse e vigor na investigação acerca da natureza do olhar, da percepção, da imagem e da própria experiência do fotográfico. Não por acaso, muitas produções de arte evidenciam um curioso aspecto relacional (interação e imersão, hibridação de meios e linguagens, citação), onde, para além do uso de diferentes suportes, importa perceber as operações que fazem dessas produções não apenas mais um objeto a ser interpretado, mas propriamente um problema a ser investigado.

2 A ideia de regularidades enunciativas inspira-se na perspectiva arqueológica de Foucault, para quem os enunciados, enquanto lógicas de formação e de distribuição de práticas discursivas e não-discursivas, podem estar dispersos em diferentes contextos e momentos históricos mas podem ser reagrupados por conservarem ou repetirem um mesmo conjunto de regras e efeitos de enunciação. 
A partir das contribuições de autores como Benjamin (1993), acerca das relações entre imagem, história e cultura, dos regimes enunciativos das imagens em Rancière, (2009, 2012) e da arqueologia dos saberes visuais propostos por Warburg (2015) e Didi-Huberman (2011), considera-se aqui a imagem como um artefato cuja fatura torna visível conjuntos de relações diversas: entre tempos, entre outras imagens e também entre discursos e modelos de representação. No contexto do que vem sendo chamado de fotografia contemporânea, o que parece caracterizar a experiência do fotográfico é o lugar que a imagem assumiria enquanto figura ou objeto de pensamento e não simplesmente algo que nos informa ou é oferecido à contemplação. Contudo, como veremos, tal lugar também não é forjado em nosso presente e sua construção pode ser entendida numa perspectiva histórica: o anacronismo.

O lugar que a experiência do fotográfico ocupa na arte hoje não é em si novo e pode ser observado já em certas expressões do pictorialismo e na fotografia documental nos séculos XIX e XX. Porém, é principalmente a partir dos anos 1970 que, na arte, a fotografia passa a privilegiar a discussão sobre a imagem e a narrativa como questões de representação e como algo que evoca e alude o real sem, contudo, desejar conter e espelhar sua verdade. Esse é o momento em que a fotografia é assumida como forma expressiva e em que muitos artistas não mais se interessarão por produzir representações da vida social e do cotidiano, mas propriamente uma investigação sobre nossos modos de ver e mostrar o mundo, atualizando a discussão sobre as relações entre arte e sociedade, arte e vida e entre a arte e suas instituições.

Se a noção da fotografia como prática cultural e histórica já foi fundamentada por diversos, é talvez com Rancière, particularmente com o que ele chamou de partilha do sensível, que a imagem fotográfica poderia ser considerada assumidamente como uma prática estética. Para Rancière, a experiência do estético é entendida como um "sistema de formas que determina a priori o que se dá a sentir" (RANCIÈRE, 2009, p. 16). Tal sistema apresenta um caráter necessariamente político por atuar diretamente sobre nossas formas de perceber e de conhecer o mundo. Da mesma forma que nos produtos midiáticos, as imagens na arte constituem e são ao mesmo tempo constituídas por sistemas de formas e discursos - práticas estéticas - que configuram o lugar que ações e discursos ocupam na partilha/divisão daquilo que elas dão a ver.

A imagem, o documento e o acontecimento tomados como construções e não simplesmente como algo capaz de revelar o mundo - e, portanto, como questões de representação e de narrativa -, é o que vem sendo discutido pelos artistas. Portanto, também no interior das práticas artísticas há procedimentos e regras que estruturam a maneira pela qual determinados objetos, imagens ou discursos ordenam nossa percepção e as relações entre presença e ausência, entre aquilo que se mostra e sua significação.

Aquilo que Rancière chamou de regime estético das artes caracteriza-se exatamente por ser um modo de mediação do sensível que não tem mais na mímese o princípio 
norteador para os processos de representação. Se na mímese há um ordenamento linear das significações e uma regulagem precisa entre as formas de inteligibilidade da representação e sua manifestação no mundo, no regime estético as regulagens entre visível e dizível parecem seguir uma lógica próxima daquilo que Benjamin (2011) chamou de alegoria. Com a alegoria, produz-se não um único sentido, mas muitos, nenhum deles literal, que se estabelecem a partir das relações entre as imagens. Dito de outro modo, diferente da metáfora que ilustra por analogia, a alegoria nos faz pensar a partir das relações entre as imagens que emparelha, sem determinar um significado prévio ou único para tais relações. Assim, na fotografia contemporânea o uso realista da descrição e do documento, por exemplo, não reiteraria literalmente o que é dado a ver, mas remeteria a um conjunto de relações distribuídas por camadas e redes de significações que é preciso rastrear espacial e temporalmente.

Essa perspectiva me parece particularmente consistente para pensar a experiência do fotográfico na arte como questão de comunicação, não apenas por permitir entender sua inscrição em determinadas lógicas enunciativas, mas também por permitir tomar distância de uma crença que faz parecer que suas concepções e modos de fazer imagem são inaugurais e autônomas. O que estou propondo aqui é pensar esses modos de fazer e de ser da fotografia contemporânea a partir das relações entre imagens e entre tempos para evidenciar a condição de conexão das práticas artísticas em fotografia com os fatos da história e da cultura e como essa condição as inscreve, tanto quanto outras práticas sociais, em regimes enunciativos que configuram a produção e a percepção de seus objetos e as relações com as coisas do mundo que eles mediam.

\section{Anacronismo e inatualidade na fotografia contemporânea}

Ao investigar as condições de individuação da fotografia contemporânea, particularmente no campo da arte, venho seguindo os traços dessas mediações observáveis em seus modos de produção, legitimação e circulação da fotografia na arte. Com isso, busco compreender as condições de possibilidade de certos modos de ver e de produzir imagens e também de dá-las a ver na atualidade. Um dos elementos que fazem parte da experiência da fotografia na arte contemporânea é sua relação com outras imagens e outros tempos, foco deste artigo.

Não é por outra razão que Rouillé (2009) argumentou que a questão do registro e da representação, por exemplo, não poderiam mais ser tratadas como se as imagens não estivessem inseridas em situações específicas e não fossem produzidas segundo certas intenções e condições técnicas, culturais e históricas. Assim, ao criticar a relação binária de aderência entre mundo e imagem - que por vezes parece balizar o entendimento do estatuto da imagem e as formas de mediação entre ambos -, Rouillé defende que, ao contrário, entre mundo e imagem existem uma série de outras imagens, "invisíveis mas operantes, que se constituem em ordem visual, prescrições icônicas, esquemas estéticos" (ROUILLÉ, 2009, p. 17). 
É a partir dessa visada que interessará aqui estabelecer um olhar sobre um dos principais elementos que participam da construção dos aspectos visuais e discursivos da fotografia na arte: a persistência de determinadas formas pré-modernas e modernas. Esse interesse pelo inatual na fotografia contemporânea, por esse algo que persiste, fundamenta-se, em parte, na questão da sobrevivência de formas de um tempo passado em outro em Warburg (2015).

As teses de Warburg de que as imagens são formas materiais e ao mesmo tempo formas de pensamento se desenvolveram e ganharam corpo em seu Atlas Mnemosyne, espécie de mapa de imagens da memória que estabelece cadeias de transporte de imagens, linhas de transmissão de características visuais através dos tempos. O mapa foi organizado em 79 pranchas contendo imagens compostas por recortes de jornal, xilogravuras, selos postais, reproduções de obras de arte e de edificações (fig. 1).

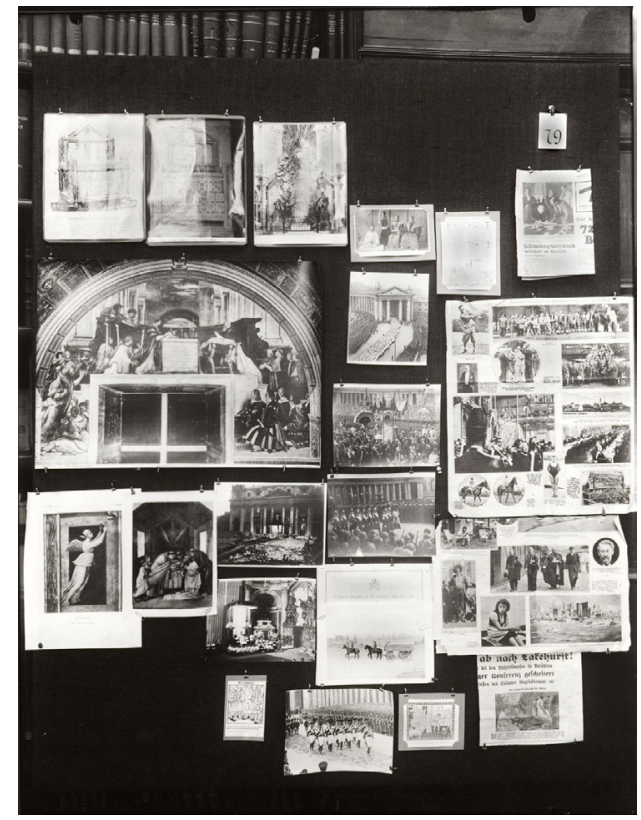

Fig. 1. Atlas Mnemosyne. Prancha 79.

As imagens não comungam, à primeira vista, de uma mesma lógica narrativa formal ou visual e nem remetem a uma mesma época ou tema, mas aparecem num mesmo plano como fruto de escolhas aparentemente fortuitas ou arbitrárias. Sua legibilidade se torna possível, porém, quando considerarmos exatamente a condição alegórica dessas imagens (num sentido benjaminiano), organizadas e dispostas para contar a história da permanência de determinados valores expressivos, que seriam transmitidos em forma de imagens, como um patrimônio sujeito a leis complexas de transformação e recepção. 
Estas são as bases do conceito wargburiano de Nachleben ou sobrevivência das formas visuais, que encontra na noção do contemporâneo em Agamben um importante aliado para se pensar a problemática colocada para a fotografia por certas imagens no campo da arte hoje. Para Agamben (2009), a própria noção do contemporâneo não seria uma resposta para os dilemas do presente, e sim uma pergunta. Para o filósofo italiano, é preciso tomar posição em relação a nosso presente ao invés de aderir totalmente a ele. Por isso, Agamben vai afirmar que para ser contemporâneo é preciso ser inatual, no sentido de se ter uma certa distância ou desconexão com o presente para então melhor poder apreender suas inflexões.

Minha hipótese é que essa tomada de distância do presente para melhor apreendê-lo em suas continuidades (ou descontinuidades) com outros tempos é importante para pensar o processo de individuação da fotografia na arte e a construção de seus aspectos visuais e expressivos. Essa distância nos permitiria evidenciar as regularidades de certos aspectos da fotografia com relação aos regimes de enunciação que de alguma forma organizaram, por exemplo, as imagens fotográficas do século XIX e da fotografia ao longo do século XX. Ao mesmo tempo, é a partir dessa abordagem que podemos nos aproximar da noção de anacronismo para evidenciar esses traços que permanecem nas imagens fotográficas desses diferentes períodos e que podem conceitualmente fundamentar as análises das imagens em nosso presente.

O termo anacronismo comumente é entendido como erro que supõe uma falta de alinhamento ou correspondência temporal entre pessoas, eventos, palavras, objetos, costumes, sentimentos, pensamentos. Podemos associar tal entendimento a uma perspectiva historicista de tempo histórico que pensa a história como tempo vazio e linear, contra a qual pensadores como Benjamin lutaram veementemente. Crucial na argumentação de Benjamin (2011), à qual nos ateremos aqui, é a noção de origem, que não deve ser entendida como gênese. É importante para o autor descolar-se de uma perspectiva que entende a história como tempo vazio para pensá-la como tempo saturado de agoras e como constructo.

Essa forma de considerar a História permitiu pensar a origem como condição de possibilidade de um acontecimento, algo que emerge de um processo de mudança e de constante reordenamento. É o que dá a Benjamin (1993) a oportunidade de salvar a espessura da história, a singularidade não do que foi mas daquilo que persiste naquilo que foi e que é no presente. Esse enfoque é importante na medida em que implica uma concepção que revê o passado na sua relação com o presente e vice-versa.

É graças a essa concepção de tempo e de história que a ideia de anacronismo tem sido discutida por diversos autores da história da arte e da filosofia. Para Rancière, por exemplo, em suas investigações sobre as relações entre estética e política, o anacronismo é pensado a partir da noção de acronia ou de inatual, como um conceito poético do qual o historiador poderia lançar mão para fazer uma leitura do presente e do passado a contrapelo: 
[...] uma palavra, um acontecimento, uma sequência significativa fora de seu tempo, dotada ao mesmo tempo da capacidade de definir as orientações temporais inéditas, de assegurar o salto ou a conexão de uma linha de temporalidade à outra. E é por essas guias, saltos é que existe a possibilidade de se fazer história. (RANCIÈRE, 1996, p. 53).

Esta noção em Rancière relaciona-se diretamente aqui com a questão da origem em Benjamin e da espessura do tempo histórico e se apresenta igualmente como uma imagem do tempo que não se fecha sobre si, mas que se desloca entre passado e presente, como algo sempre incompleto, inacabado e em constante mudança. Tanto quanto para Benjamin, para Rancière, o que foi e o que é são acronias, agoras que podem ser recuperados por uma operação de montagem de tempos dentro de outros tempos, como propõe Didi-Huberman (2011).

Já o historiador da fotografia Michel Poivert (2010) vê uma relação anacrônica que têm certas imagens contemporâneas, sobretudo as que têm como tema a mise-en-scène e as relações entre realidade e ficção. Pensando no aspecto de artificialidade da pose, por exemplo, Poivert vai ver esta prática ou tematização como algo recorrente na fotografia desde seus primórdios. Contudo, argumenta que a produção atual se inscreve numa relação temporal que não se reduz à ordem técnica do registro e da documentação, mas numa relação contemporânea com a teatralidade. Para este autor, a fotografia contemporânea não reproduziria em si o que já foi feito na primeira fotografia e na fotografia moderna, mas inventaria com elas uma outra relação: não mais uma revelação do mundo, mas a evidência do caráter artificial e intencionado de sua construção. Nem apenas ficções ou simulacros, mas formas visuais que partem do documento para fazer imagens. Um exemplo disso seriam trabalhos que recuperam as práticas dos tableaux-vivants, encenação de obras pictóricas utilizadas na fotografia do século XIX, particularmente no pictorialismo (FABRIS, 2011).

Atento às históricas tensões trazidas pelo artifício na produção da imagem e às controvérsias relativas ao real e ao ficcional na fotografia, diversos artistas trouxeram tais questões para o centro das discussões sobre a imagem, empregando, por vezes, alguns dos procedimentos usados pelos pictorialistas, como a citação, a encenação e a fotomontagem. Um desses artistas é o canadense Jeff Wall, cuja obra constitui-se basicamente da encenação literal ou inspirada em obras de arte, da encenação de situações imaginárias ou de cenas vistas ou vividas por ele próprio. Em Wall, as relações estabelecidas entre documento, narrativa e citação, por meio da encenação e das referências à história da arte, às imagens midiáticas ou ao cotidiano, estão diretamente ligadas à atual discussão, nos campos da arte e da comunicação, sobre os regimes de enunciação do visível, ou seja, sobre as condições que regulam as relações entre ver e mostrar, fazer e dizer.

Como outros artistas que trabalham com fotografia, Wall não está interessado em simplesmente mostrar a realidade ou contar histórias sobre o mundo, mas de reencenar o teatro do mundo através da fotografia. É o que ocorre na imagem abaixo (fig. 2), 
meticulosamente produzida e encenada por Wall, além de ser digitalmente manipulada, para parecer espontânea e real, quando, na verdade, seu interesse é problematizar noções como factualidade e objetividade através do uso intencionado da construção da imagem e das questões herdadas da história da arte com relação à forma quadro na pintura (FRIED, 2012).

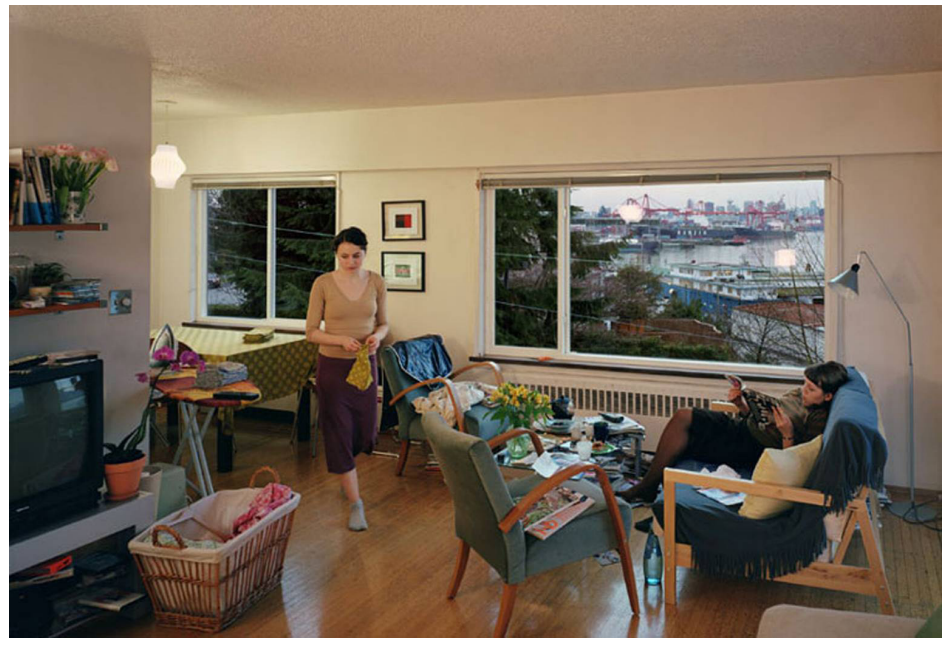

Fig. 2. Jeff Wall. View from an appartment, 2004.

Nesse trabalho, toda uma estrutura foi montada para realizar a fotografia, desde a organização das personagens e seu vestuário, até a montagem do cenário. Wall aluga um apartamento, chama duas mulheres e pede que elas o mobiliem como desejarem e se comportem como se estivessem em casa (FRIED, 2012). Visualmente, o resultado é aparentemente uma cena banal de um cotidiano privado, quando, na verdade, se trata da descrição editada de uma cena banal de um certo cotidiano privado. A encenação de Wall de obras de arte ou de situações do cotidiano busca questionar a dicotomia real-ficcional, suplantando-a pela produção de um real performado (POIVERT, 2010), procedimento muito próximo de experiência de documentaristas contemporâneos como Eduardo Coutinho, por exemplo.

Retomando a questão do anacronismo, outro historiador da arte que discute e faz uso do termo é Daniel Arrasse (2007). Para ele, o anacronismo é pensado como prática crítica que pensa seu tempo recorrendo a outros tempos, não como simples alusão ou citação mas como forma de tensionar diferentes temporalidades. Graças a esse tensionamento, seria possível colocar em questão a relação da contemporaneidade da arte contemporânea com o nosso presente, na medida em que se evidencia o interesse por questões que não se reduzem à documentação e à representação mimética do real, o que de certa forma revela parte do funcionamento do pensamento sobre a imagem na arte em nosso presente. 
Arrasse está interessado em entender o jogo de relações que a obra de arte realiza e em como o artista nos faz ver a arte e o que ele nos faz ver quando nos faz ver arte. Para Arrasse, analisar uma imagem, seja pintura ou fotografia, não trata apenas de posicionar a obra, a série de que faz parte ou o artista no contexto de sua produção. Antes, Arrasse sugere que se procure ver na imagem as relações e questões que as constituem a partir de elementos como verossimilhança, citação, apropriação e reinvenção.

Nesse sentido, este autor vai se interessar, por exemplo, pela questão da representação do indivíduo na tradição do autorretrato na história da arte. Dentre diferentes análises nesse campo, Arrasse realizou uma aproximação entre o pintor moderno alemão Max Beckmann (figs. 3 e 4) e a artista americana Cindy Sherman (figs. 5 e 6). O primeiro é um pintor modernista pertencente ao movimento da Nova Objetividade, conhecido por suas sátiras e críticas à sociedade alemã do entre-guerras e à ascensão do nazismo. A segunda é conhecida por seus stills fotográficos que a encenam desde os anos 1980, em múltiplas identidades femininas no contexto da cultura de massa, dos filmes B hollywoodianos e da própria história da arte.

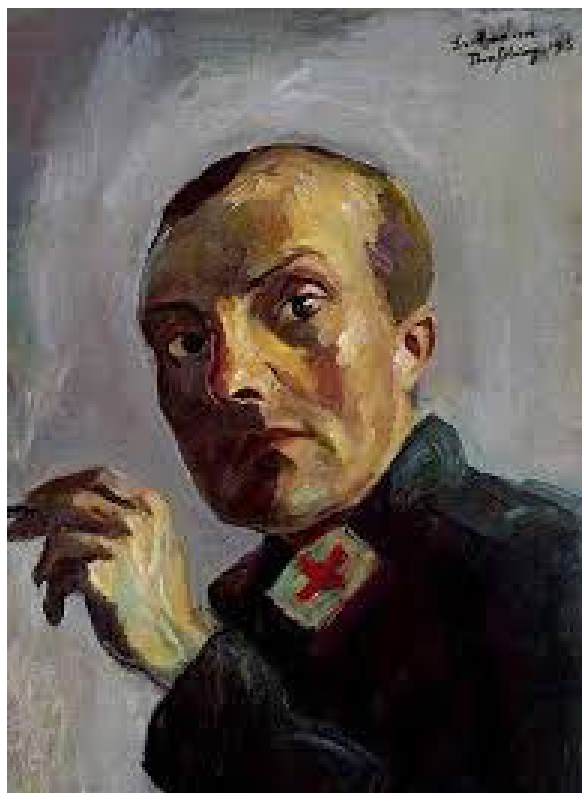

Fig. 3. Self-portrait as nurse, 1938.

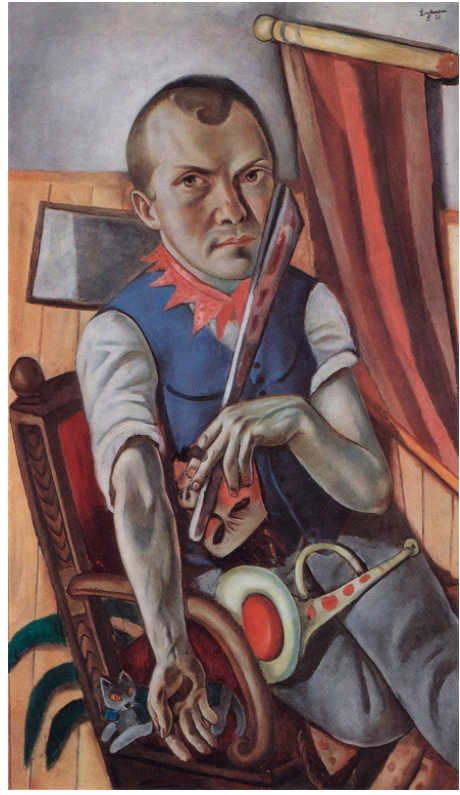

Fig. 4. Self-portrait as clown, 1921. 


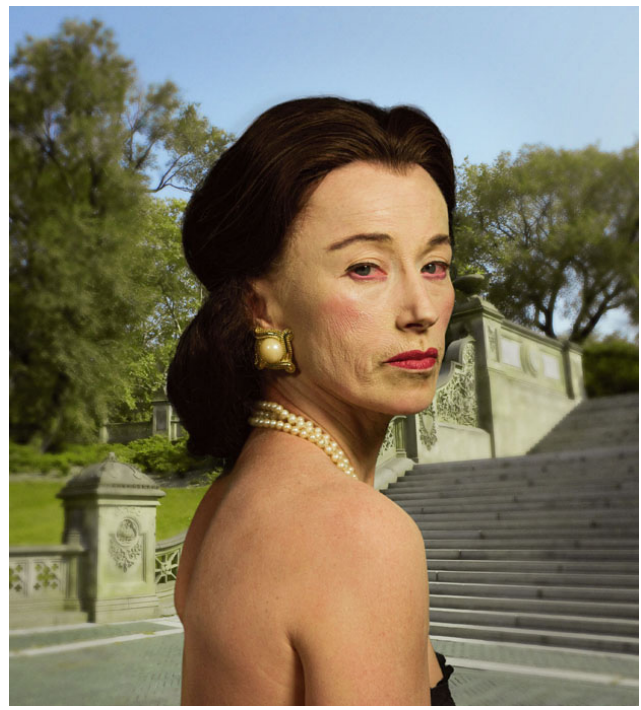

Fig. 5. Untitled 465, 2008.

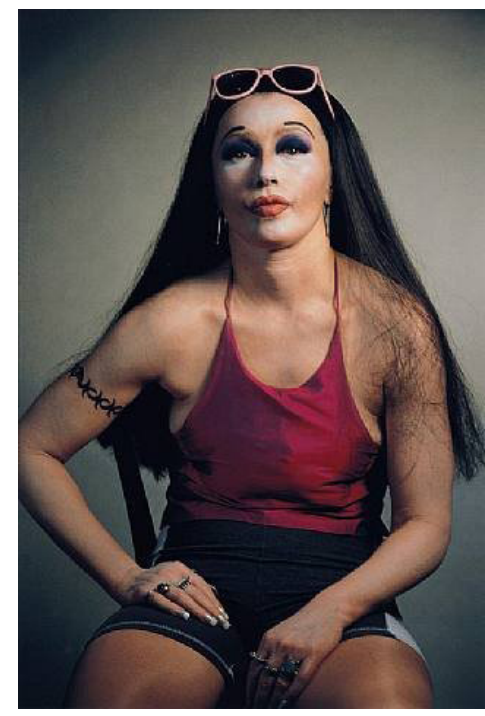

Fig. 6: Untitled 355, 2000.

Nessa aproximação, ficam claras as estratégias tanto de Beckmann quanto de Sherman de reencenar-se como outro como forma de tratar de tema sociais, da mídia e da cultura. Fica claro também que as imagens são construídas e ressignificadas a partir da relação com outras imagens e com outros tempos e que o gesto de releitura do passado e de um pensamento crítico sobre os modelos de representação de si não é inaugurado pela arte contemporânea. Como observa Arrasse, tanto a fotografia de Sherman remete aos procedimentos das pinturas de Beckmann, quanto a pintura de Beckmann remete, por sua vez, às obras de Rembrandt (por suas formas de representação da condição humana) e às de Picasso (pela confrontação da arte com a vida pessoal do artista e pelas reflexões sociais e políticas sobre seu tempo).

Finalmente, mas não menos importante, a noção de anacronismo em Didi-Huberman é vista como epistemologia ou método que permite cartografar as relações entre imagem e história, através daquilo que persiste na imagem: lampejo, resquício, espessura. Para o autor, a imagem "não é a imitação das coisas, mas o intervalo feito visível, a linha de fratura entre as coisas" (DIDI-HUBERMAN, 2011, p. 166). A imagem para ele deve ser entendida como resultado de uma operação de montagem, como algo que resulta de um trabalho de organização/ordenamento de elementos descontínuos e de uma posterior recomposição estrutural.

Inspirado fortemente na noção benjaminiana de imagem dialética, entendida como fulguração e espaço de colisão e rebatimento entre tempos e coisas, as noções de montagem, fratura ou intervalo em Didi-Huberman apontam para a imagem como experiência resultante de gestos de uma fabricação ancorados na experiência concreta 
do mundo. $\mathrm{O}$ anacronismo seria para este autor exatamente um procedimento - inspirado em Warburg - usado para rastrear e pensar esses intervalos entre-tempos e entre-coisas através da aproximação ou do confrontamento de elementos heterogêneos. Graças a esse procedimento seria possível pensar a imagem como lugar de produção do acontecimento, um lugar, portanto, de tensionamento de nossas formas de conhecimento: nem pura verdade sobre algo, nem sua pura ilusão, mas ponto de contato possível com o real e como uma narrativa possível a respeito e a despeito desse real. Por sua vez, essa concepção de imagem pensada como intervalo e produção é tributária de outra noção benjaminiana: a do conhecimento ou da epistemologia por montagem.

Para Didi-Huberman, a noção de anacronismo permitiria retomar a problematização benjaminiana da história e do conhecimento pelo passado e pela memória e seus vestígios, evidenciando que o que é próprio da história e da memória é ser uma narrativa feita ao mesmo tempo de fragmentos de elementos factuais e ficcionais recortados e remontados de determinados modos. Se a imagem não constitui simplesmente um documento que remete a um acontecimento no tempo, mas a algo que "fulgura" e se move por sua inscrição em dinâmicas enunciativas e de releituras constantes, para Didi-Huberman, leitor de Benjamin, imagem e história só podem ser entendidas como formas de produção de conhecimento, como operações que articulam e "montam" tempos históricos, formas narrativas e de representação, de modo a dar legibilidade à experiência.

\section{Considerações finais}

Desenvolvida por distintos autores e apresentada aqui brevemente, a noção de anacronismo pode constituir um importante operador teórico e metodológico para os estudos da fotografia e suas implicações para a compreensão dos regimes enunciativos do fotográfico na atualidade.

Juntamente com outros recursos, a noção do anacronismo pode nos ajudar a estabelecer uma outra forma de pensar as imagens em nosso tempo: não a partir de uma hermenêutica ou de um historicismo produtor de novos símbolos e representações, mas da espessura própria das imagens e de seus processos de produção, circulação e legitimação no campo social como redes de relações observáveis numa perspectiva histórica. Se o passado é saturado de agoras, como afirmava Benjamin, assim também o é o presente: uma montagem multitemporal formada por elementos e referências diversas (fatos, tempos, códigos visuais, discursos, formas de representação).

Mesmo pertencendo a épocas distintas, os tipos de discursividade visual de obras pictóricas e fotográficas podem inscrever-se numa mesma atitude diante da técnica e da narrativa, ou seja, num mesmo regime enunciativo que favorece o deslocamento de um pensamento sobre a imagem fotográfica como traço do real e objeto de verdade da memória e do testemunho para a condição de um artefato que se produz nos jogos de 
produção de sentido para a memória e para as representações do mundo. Com isso, a visada inatual da fotografia contemporânea evidencia a natureza híbrida da imagem como documento e invenção, inscrita numa permanente negociação entre o testemunhal, o dizível e o visível.

Curiosamente, muitas das fotografias produzidas e apresentadas no circuito da arte contemporânea no Brasil e no exterior trazem traços e características que parecem encontrar ressonâncias na chamada primeira fotografia e também na fotografia moderna. Observando trabalhos de artistas como Nam Goldin, Thomas Struth, Sophie Ristelhueber, Rineke Dijskstra, Candida Hofer, Andreas Gursky e, no Brasil, Rosângela Rennó, Alice Miceli, Pedro David, Patricia Gouvea, Marcelo Tinoco, para citar apenas alguns, é possível verificar não apenas a recorrência de temas (retrato e autorretrato, paisagem, natureza-morta) da história da arte, mas principalmente um fazer imagem que parece reler criticamente formas de fazer imagem e de produzir narrativas no mundo. Como em Wall e Sherman, nas obras desses e de outros artistas, retratos, paisagens e eventos não estão interessados em produzir apenas registros de pessoas, lugares e coisas, mas, graças aos jogos que realizam entre imagens e entre tempos, buscam inventariar e discutir alegoricamente nossas relações com a história, com identidade, com o corpo, os espaços naturais e construídos.

Portanto, mais que uma nova categoria, a fotografia contemporânea seria, portanto, a forma social e histórica que discute tanto o abalo na crença da verdade absoluta do índice, do documento e do testemunhal, nas noções de belo, de gênero e de narrativa quanto os rearranjos desses elementos na atualidade. Provavelmente é a partir dessas novas formas de pensar a imagem que possamos entender uma fotografia que trata a imagem como artefato ao mesmo tempo técnico e social e como forma de pensamento sensível no mundo e não apenas sobre o mundo. É também possivelmente a partir dessa perspectiva que se possa entender como se constrói para esta fotografia um estatuto de dispositivo que inventaria e problematiza a experiência e discute modelos de representação e modos de ver e dizer o mundo.

Ao evidenciar as relações entre tempos através de memórias e narratividades visuais que se constituem como nós temporais heterogêneos, minha aposta é que o que persiste enquanto anacronismo no presente da fotografia na arte é o que justamente constitui sua relevância para os estudos da comunicação: a possibilidade de problematizarmos as formas de mediação da experiência social através da imagem. Ao permitir articular diferentes instâncias discursivas e não-discursivas no seio da própria imagem, o anacronismo desloca nossos modos de ver e de representar e evidencia o funcionamento alegórico da fotografia na arte e as cartografias poéticas que ela produz de nossas sociedades. Finalmente, se o anacronismo nos permite ser contemporâneos, como entende Agamben, então entrecruzar passado, presente e futuro pode ser uma aposta na potência da fotografia e nas possibilidades que ela nos oferece para realizar uma leitura inatual de próprio nosso presente. 
Fernando Gonçalves é professor e pesquisador do Programa de Pós-graduação em Comunicação da Uerj. É doutor em Comunicação pela ECO-UFRJ.

goncalvesfernandon@gmail.com

\section{Referências}

AGAMBEN, G. O que é o contemporâneo? e outros ensaios. Chapecó: Argos, 2009.

ARRASSE, D. Anachroniques. Paris: Gallimard, 2007.

BENJAMIN, W. Magia e Técnica, Arte e Política. Obras escolhidas, vol.1. $6^{\text {a }}$ edição. São Paulo: Brasiliense, 1993.

Origem do Drama Barroco Alemão. São Paulo: Brasiliense, 2011.

DIDI-HUBERMAN, G. Ante el tempo: historia del arte y anacronismo de las imagenes. Buenos Aires: Adriana Hidalgo, 2011.

FABRIS, A. O desafio do olhar: fotografia e artes visuais no período das vanguardas históricas, vol. 1. São Paulo: Martins Fontes, 2011

FRIED, M. Why Photography matters as art as never before. 4th ed. New Haven and London: Yale University Press, 2012.

LISSOVSKY, M. Máquina de esperar. Rio de Janeiro: Mauad, 2008.

POIVERT, M. La Photographie Contemporaine. Paris: Flammarion, 2010.

RANCIERE, J. A partilha do sensível. 2 ${ }^{a}$ ed. Rio de Janeiro: Ed. 34. 2009. . Le concept d'anachronisme et la vérité de l'historien. L'Inactuel, nº 6, p.53-68, automne, 1996. O espectador emancipado. São Paulo: WMF Martins Fontes, 2012.

ROUILLÉ, A. A fotografia: entre documento e arte contemporânea. São Paulo: Senac, 2009.

WARBURG, A. Histórias de fantasmas para gente grande. São Paulo: Companhia das Letras, 2015. 